\title{
Characterization Analysis in Abdurrahman Munif's Sibaq al-Masafah al-Thawilah (Long-Distance Race)
}

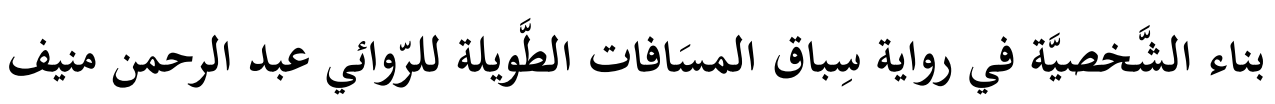

\section{Mohammed Eid A Alotaibi}

mmff2008@hotmail.com

Department of Arabic Language and Literature

King Saudi University, Saudi Arabia

• Received: 20.05.2021 • Accepted: 11.10.2021 • Published online: 20.11.2021

Abstract: The research aims to study character building in Abdul Rahman Munif's novel The Long Distance Race. The writer has sought to convey his novelistic characters through narrative and creative ways, such as using multiple patterns to highlight its varied qualities and features. His study used the structural approach, but benefited from other critical techniques as necessary given the study's nature. The investigation found several key findings, including: First, the narrator does not reveal most of the novelistic characters' traits, but rather those that serve the story's circumstances and goals. Because the narrator depended on presenting the physical component in two ways: telling and showing, it is vital in establishing the primary character. Second: The physical dimension is an important part in building the main character. Third, the psychological component shows us the personality's psychological states, emotions, and feelings, as seen in the psychological battle that the hero Peter has with Bashir, and how he attempts to avoid falling in love with her and racing towards her. Fourth, the writer elected to blend the two narrators, resulting in a mixed vision called dual vision. Fifth, the novel's writer did not give the character the role of showing himself. Most of the characters have suggestive implications, manifested via their position and direction in the world of narration, thereby forging the connection between the meaning of the character's name and the path of the novel's events.

Keywords: Dialogue, narration, Character's Personality, Sibāq Al-Masāfāt Al-Ṭawilä̈ 
Mohammed Eid A Alotaibi

الملخص: يهدف البحث إلى دراسة بناء الشخصية في رواية عبد الرحمن منيف "سباق المسافات الطويلة". سعى الكاتب إلى نقل شخصياته الروائية بطرق سردية وإبداعية ، مثل

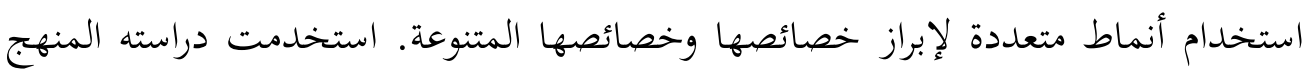
الهيكلي ، لكنها استفادت من تقنيات نقدية أخرى حسب الضرورة نظرًا لطبيعة الدراسة. توصل التحقيق إلى عدة نتائج رئيسية ، منها: أولاً ، لا يكشف الرئفي الراوي عن معظم سمات

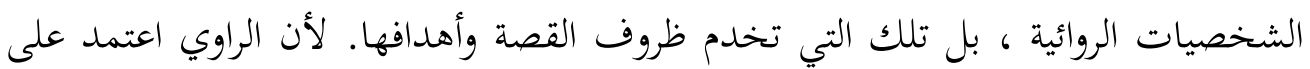
تقديم المكون المادي بطريقتين: الحكي والعرض ، فهو أمر حيوي في تأسيس الشخصية الأساسية. ثانيًا: البعد المادي جزء مهم في بناء الشخصية الرئيسية. ثالثًا ، يُظهر لنا المكون النفسي الحالات النفسية للشخصية وانفعالاتها ومشاعرها ، كما يظهر في المعركة النفسية التي خاضها البطل بيتر مع بشير ، وكيف يحاول تجنب الوقوع في حبها والتسابق نحوها. رابعًا ، اختار الكاتب أن يدمج بين الراوبين ، مما أدى إلى رؤية مختلطة تسمى الرؤية المزدوجة.

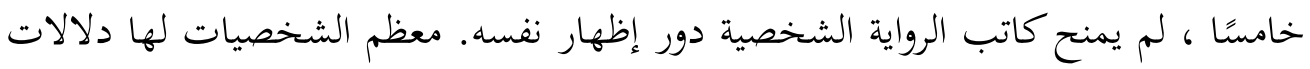
إيحائية ، تتجلى من خلال موقعها واتجاهها في عالم السرد ، مما يؤدي إلى إقامة صلة بين معنى اسم الشخصية ومسار أحداث الرواية.

كلمات دلالية: الحوار، السرد، الشخصية، سباق المسافات الطَّيلة

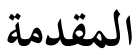

تعد الشخصية من أهم الركائز التي يقوم عليها العمل الروائي، وتكمن أهميتها في أن الرواية تعتمد من خلال تركيزها على الإنسان ومشكلاته على عنصر الشخصية؛ ليبث الروائي بواسطتها الأفكار والاتجاهات والمعاني، فهي أشبه بالقناع الذي يلبسه الروائي، حتى يمارس حريته المطلقة في بث ما يريد من تلك الأفكار والمعاني، وهذه الشخصية المقنعة يعده النقاد أساس بناء الرواية ونجاحها، فقد ظل مفهوم الشخصية غفلا لفترة طويلة، من كل تحديد نظري أو إجرائي دقيق مما جعلها من أكثر جوانب الشعرية غموضا وأقلها إثارة لاهتمامات النقاد 
Mohammed Eid A Alotaibi

والباحثين. ويفسر تودوروف هذا الإعراض عن دراسة الشخصية الروائية بكونها، هي نفسها، ذات طبيعة مطاطية جعلتها خاضعة لكثير من المقولات دون أن تستقر على واحدة منها، كما أن هذا الإعراض يتضمن موقفا بمثابة رد فعل على الاهتمام الزائد بالشخصية والانقياد الكلي لها (بحراوي، 2009 ص207).

وكانت الشخصية تستخدم في حقل علم النفس، حيث تأثر به المؤلفون المسرحيون الذين أقاموا كثيرا من مآسيهم حول الخوف من قوة الغرائز. فالحوافز الغريزية المتسلطة التي تجرف صاحبها إلى الدمار هي موضوعات شكسبير في رواياته "ماكبث، وانطونيو وكيلوباترا". وكان شكسبير يميل إلى عزل الشخصية، وإبعادها عن دعاماتها المألوفة في البيئة الاجتماعية، إلى أن يتأمل الرجل الواقعي ينبثق من وراء القناع الاجتماعي (عبّاس، 1982 ص15). وفي القرنين السابع والثامن عشر في إنكلترا، نجد أن الشخصية صورة خاطفة أو تحليلا وصفيا لفضيلة معينة أو رذيلة معينة، كما تتمثل في شخص وهو ما نسميه اليوم على الأغلب صورة لطباع الشخصية (فتحي، 1986 ص210-211).

أما في القرن التاسع عشر عندما احتلت الشخصية مكانا بارزا في الفن الروائي أصبح لها وجودها المستقل عن الحدث، بل أصبحت الأحداث نفسها مبنية أساسا لإمدادنا بمزيد من المعرفة بالشخصيات، أو تقديم شخصيات جديدة. ويربط "ألان روب غريبي" هذا الاهتمام الذي أولاه روائيو القرن التاسع عشر للشخصية بصعود قيمة الفرد في المجتمع ورغبته في السيادة أي ما أسماه بـ" العبادة المفرطة للإنساني" وهذا ما يفسر كون الشخصية لديهم كانت تختزل مميزات الطبقة الاجماعية، وأصبحت كل عناصر السرد تعمل على إضاءة الشخصية وإعطائها الحد الأقصى من البروز، وفرض وجودها في جميع الأوضاع (فتحي، 1986 . 
Mohammed Eid A Alotaibi

ويعد جينيت الشخصية أثرا من آثار الخطاب، ولكنها لا تنتمي إليه بل إلى الحكاية. وهو يفضل دراسة الوسائل التي يستخدمها في رسم الشخصية، أي التشخيص، بدلا من دراسة الشخصية مباشرة. أما غريماس فيستخدم بدلا من مصطلح الشخصية مصطلحين متكاملين هما: (العامل والممثل)، وهو يدرس الشخصية انطلاقا من ستة أدوار ثابتة ممكنة (العوامل)؛ وقد تُمثّل الشخصية دورين أو أكثر، وقد يمثّل الدور الواحد أكثر من شخصية واحدة (زيتوني، .(115) 2002

وفي عالمنا العربي نجد أن مصطلح الشخصية، يحيطه الالتباس، حيث نجد معظم النقاد العرب يصطنعون مصطلح "الشخص"؛ وهم يريدون الشخصية، ويجمعونه على شخوص. والحق أن اشتقاق اللغة العربية يعني من وراء اصطناع تركيب:" ش خ ص "، وذلك كما نفهم نحن العربية على الأقل، من ضمن ما يعنيه، التعبير عن قيمة حية عاقلة ناطقة. فكأن المعنى إظهار شيء وإخراجه وتمثيله وعكس قيمته. ولا يعني أصل المعنى في اللغات الغربية إلا شيئا من ذلك؛ إذ إن قولهم Personnage《:إنما هو تمثيل وإبراز وعكس وإظهار لطبيعة القيمة الحية العاقة الماثلة في قولهم الآخر .Personne» فالمسألة الدلالية، وقبلها الاشتقاقية في اللغات الغربية محسومة؛ بينما هي في اللغة العربية معرضة لبعض الاضطراب؛ لأننا لو مضينا على تمثل الدلالة الغربية وفلسفة الاشتقاق في اللغة الفرنسية خصوصا؛ لكان المصطلح هو "شْخصنَة" لا "شخصية"، وذلك على أساس أن الشخصنة مصدر متعد يدل على تمثيل حالة بنقلها من صورة إلى صورة أخرى (مرتاض، 1998 ص74 ـ 75). ويعلق الدكتور عبد الملك مرتاض على هذا بقوله: "وأيا كان الشأن، فإن المصطلح الذي نستعمله نحن مقابلا للمصطلح الغربي 》Personnage《 هو شخصية 》؛ وذلك على أساس أن المنطق الدلالي للغة العربية الشائعة بين الناس يقتضي أن يكونه الشخص 》هو الفرد 
Mohammed Eid A Alotaibi

المسجل في البلدية، والذي له حالة مدنية، والذي يولد فعلا ويموت حقا. بينما إطلاق الشخصية لا يخلو من عمومية المعنى، في اللغة العربية، زئبقي الدلالة فارتأينا تمحيضه، لدى الحديث عن السرديات، للعنصر الأدبي الذي يظفر في العمل السردي ضمن عطاءات اللغة التي يغذوها الخيال للنهوض بالحدث، وللتكفل بدور الصراع داخل هذه اللعبة السردية العجيبة" (مرتاض، 1998م، ص75).

بيد أن الثورة العارمة على الشخصية الروائية، لم تجد صداها إلإعند رواد الرواية الجديدة وأنصارهم، ولم تبلغ الصورة التقليدية في بناء الشخصية، وما زال عدد كبير من الروائيين في رك الشرق والغرب، يحفظون للشخصية مكانتها التي حققتها لها الرواية الواقعية، ويحرصون في أعمالهم الروائية على بناء شخصياتهم بناء متكاملا يشمل كافة أبعادها (الحازمي، 2009م، ص198). وتعد الشخصية من أبرز مشكلات العمل الروائي بسبب طبيعتها التي تتطلب تقنيات سردية مختلفة حتى تتكوّن وتتشكّل بصورة تتلاءم مع المضمون الحكائي، لذا حاول الباحث من خلال رواية (سباق المسافات الطويلة) للروائي عبد الرحمن منيف، أن يدرس طبيعة الشخصية الروائية، وكيفية بنائها داخل العمل الورائي. منهجية البحث

اعتمد البحث على المزج بين المنهج البنيوي الذي يعتبر أداة إجرائية ومنهجا من مناهج البحث الحديثة كونه يعمل على مقاربة بنية السرد الروائي من الداخل أي الوقوف على الناحية الفنية، إضافة إلى المنهج السيميائي الذي ينفتح على الدلالات القريبة والبعيدة، السطحية والعميقة للنص. - n

نتائج الدراسة وتحليلها بناء الشخصية: تقديم الشخصية 
Mohammed Eid A Alotaibi

ميّز النقاد بين طريقتين متبعتين في تقديم الشخصية الروائية: الطريقة الأولى: طريقة الإخبار أو الطريقة المباشرة: وهي أن يقدم الشخصية بصورة مباشرة من خلال إخبارنا عن طبائعها وأوصافها، أو يسند ذلك إلى شخصيات تخيلية أخرى أو حتى عن طريق الوصف الذاتي. أما

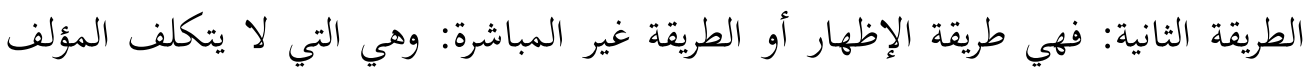
شيئا، حيث يترك القارئ أمر استخلاص النتائج والتعليق على الخصائص المرتبطة بالشخصية، وذلك سواء من خلال الأحداث التي تشارك فيها أو عبر الطريقة التي تنظر بها تلك الشخصية إلى الآخرين (بحراوي، 2009م، ص223). ففي رواية سباق المسافات الطويلة، نجد أن الكاتب استخدم في تقديم شخصيات الرواية كلتا الطريقتين -طريقة الإخبار وطريقة الإظهار - لمريه

$$
\text { في تقديم الشخصية الروائية. }
$$

قدّم الكاتب شخصية "بيتر" باستخدام الطريقتين -المباشرة وغير المباشرة- ففي الطريقة غير المباشرة نجد أن الكاتب يكشف من خلال الأحداث الروائية صفات جديدة للشخصية، ليحفّز عنصر التشويق في نفس المتلقي، ويثير فضوله لمعرفة المزيد عن صفاتها الأخرى، وهذا

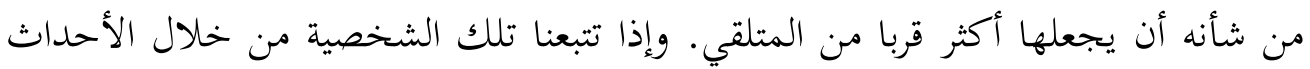
السردية، نجد أنها تتمتع بإخلاص وتفان في العمل، ولعل هذا السبب هو الذي قاد بريطانيا للاعتماد عليه في للقيام بتلك المهمة الصعبة والخطيرة معا. ومن الأقوال والأفعال التي تدل على ذلك حواره مع زوجته باتريشيا عن مخاطر السفر إلى الشرق، وموقفه اتجاه ذلك الواجب

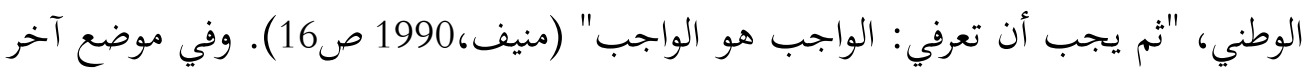
يرى أن "إخلاصه للعمل في كثير من الحالات يؤرقه كثيرا، حتى أن خطيئة مهما كانت صغيرة، يمكن أن تسبب له حالة عصبية، لا يعرف كيف يقاومها، أو يتغلب عليها، وهذه الصفة بالذات، رغم أنها سبب من العذاب الذي يعانيه، وحتى السوداوية والشك في حياته، هذه الصفة ذاتها كانت وسيلة للتقديم في العمل، وكانت الرابطة الخفية التي تشده إلى رؤسائه أو تشد رؤساءه إليه" (منيف، 1990 ص26). يتضح من المقطع السابق أن الشخصية تتصف في في 
Mohammed Eid A Alotaibi

بالعصبية التي تصل إلى درجة لا يمكنها أن تسيطر على نفسها، كما أنها ذات نظرة سوداوية للحياة، ينتابها الشك فيما حولها، إلا أنها في المقابل شخصية مخلصة تريد أن تكون في موضع ثقة عند رؤسائها وأصدقائها "إنه كعادته دائما يريد أن يكون موضع ثقة رؤسائه

$$
\text { وأصدقائه" (منيف، موصعة } 1990 \text { ص13). }
$$

وإلى جانب صفة الإخلاص نجد أنها تتمتع أيضا بثقافة عالية من خلال اطلاعها الواسع على الثقافات الأخرى، حيث تسأل فباتريشيا "بيتر" عن الشرق، رغم أنها تعلم أنه لم يسبق له

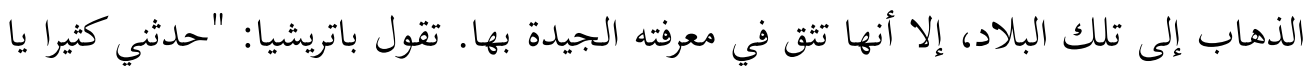

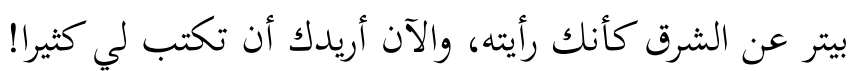
ـ هذا الشرق الوغد العفن، أي شيء يمكن أن يكتب الإنسان عنه! (منيف، 1990ص10.

ويبدو من هذا الحوار أن "بيتر" إلى جانب ثقافته الواسعة، شخصية محبة للكتابة والتأليف، ومن ذلك ما جاء في قوله: "كنت أقدر أن أنتهي من كتابة أشياء من كتابة أشياء هذه الشتاء، إلى جانبك يا باتريشيا! لما وجدها صامتة وبعيدة أضاف : ـ لا أدعي أن هذا الكتاب لي وحدي... إنه لنا نحن الاثنين. ابتسمت باتريشيا بحزن، قالت وهي تهز رأسها : ـ إنه لك يا بيتر، وحدك الذي تصنعه، وعملي معك لا يتعدى الجلوس إلى جانبك وأنت

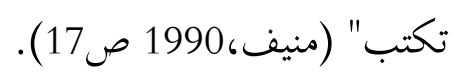

كما نجد أن هذه الشخصية -شخصية بيتر - تحب صيد الأسماك، حيث يرى "أنه لا يستطيع أن يتخلى عن الذهاب إلى بيفرلي يوم السبت مساء لكي يكون صباح الأحد في المكان الذي اختاره للصيد" (منيف،1990 ص13). ويتضح من هذا أنه يمارس هوايته كل

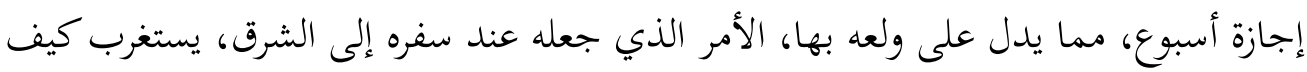
ينقطع عن تلك الهواية المحببة لديه فترة طويلة؟ ! "قالت باتريشيا بأسى، لكن بسخرية 
Mohammed Eid A Alotaibi

ـ وهناك سوف تجد أماكن كثيرة للممارسة هوايتك! نظر إليها بحزن ثم هز رأسه وقال :

ـ لن يتاح لي أن أضيف كلمة واحدة إلى الكتاب قبل العودة إلى هنا..." (منيف، 1990

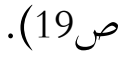

إن شغفه وولعه بصيد الأسماك، جعله يؤلف كتابا عن "أسماك اليتماكوس"، لكنه لم يستطع أن ينتهي من كتابته، بسبب المهمة الجديدة التي جاء من أجلها. فكل الصفات

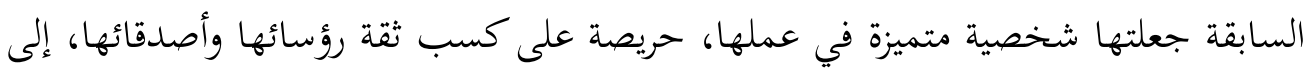
جانب ثقافتها الواسعة المستمدة من خلال القراءة الدؤوبة والاطلاع المستمر، ما جعل منها شخصية محبة للتأليف والكتابة. فكل الصفات السابقة التي اكتسبتها الشخصية، عمد الراوي إلى تقديمها بطريقة غير مباشرة، جاعلا القارئ يستنتج صفاتها من خلال أقوالها وردود أفعالها، ومن حواراتها مع غيرها من الشخصيات، أو مع نفسها.

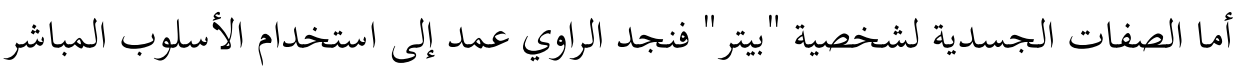

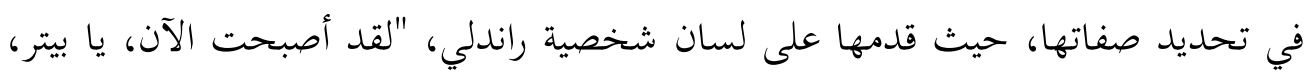

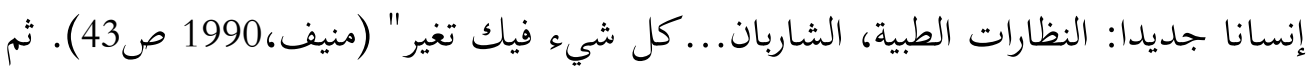

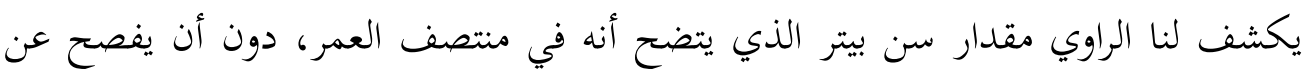
عمره بالتحديد. "صحيح أنه لم يعد شابا، لكنه لا يبدو كهلا أو مسنا" (منيف، لهن، 1990 ص52) . نلاحظ مما سبق أن الراوي لم يكشف لنا عن صفات شخصية "بيتر" بصورة مباشر، بل جعل القارئ يستنتجها من أحداث الرواية التي يتجّلى من خلالها أبعاد الشخصية بصورة تدريجية،

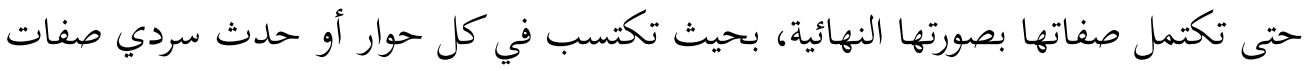
جديدة تضاف إلى صفاتها السابقة، لغرض فني معين يتصل بسياق الحكي ومقاصده، فمثلا

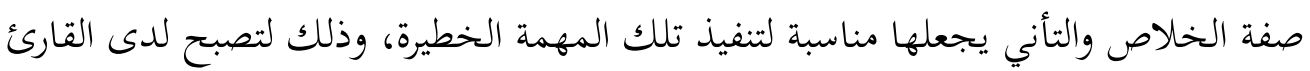
القناعة بكفاءتها للقيام بتلك المهمة الخاصة، فقد بيّن مدى صبرها وتحملها، من خلال استحضار زمنها الماضي، عندما كانت تعمل في الميدان العسكري، حيث شاركت في الحرب 
Mohammed Eid A Alotaibi

العالمية الثانية، وتعرضت إلى الأسر من قبل الألمان، لا شك أنها شخصية كسبت الصبر والتحمل، وجديرة بمواجهة الصعاب.

\section{شخصية راندلي}

جاء تقديم شخصية "راندلي" بطريقة مباشرة بواسطة الراوي الذي وصف سلوكها وملامحها الخارجية. "كان أحدهما مسنا ثقيل الحركة، وجهه قاسي الملامح، خاصة بالحواجب الكثيفة التي تجلل عينه" (منيف،1990 ص28). ثم نجد أن هذه الشخصية تكتسب صفات جديدة على لسان بيتر،"والمستر راندلي رجل لا يحب الخطأ ولا يقبل أي

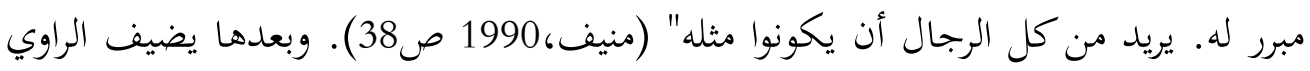
عن طريق شخصية بيتر ـ كذلك ـ بعض الملامح والصفات "وحين نظر إلى وجه راندلي مباشرة وجد أن الشعيرات الحمراء تنتشر بكثرة على هذا الوجه وتلوحه، فبدا غامضا ومنفرا وغريبا، ولم يستطع أن يقول شيئا!" (منيف،1990 ص40). ويمكن أن نجمل أهم صفاته الشخصية، وهي: (رجل كبير السن، بطيء الحركة، كثيف الحواجب، تنتشر في وجهه الشعيرات الحمراء، حريص، متقن في عمله، غريب، منفر، غامض). شخصية باتريشيا

جمع الراوي في تقديم شخصية "باتريشيا" بين طريقتين: الطريقة المباشرة، وغير المباشرة،

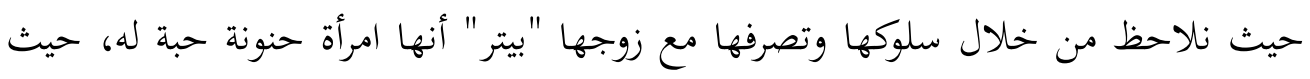

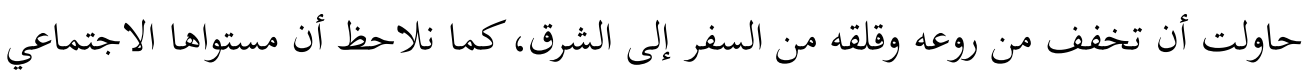

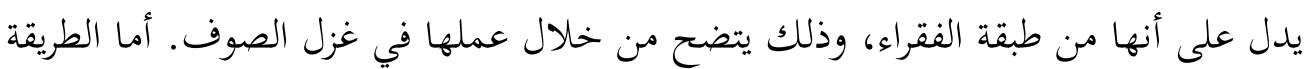
المباشرة التي قدمت بها تلك الشخصية "كانت باتريشيا تمتلك مقدارا من الوضوح والوسامة والصمت" (منيف،1990 ص51). فهي امرأة على قدر من الوسامة والجمال، إلى جانب أنها تتصف بالغموض وعدم والوضوح، وذلك ما دلّت عليه صفة الصمت. شخصية عبّاس وشيرين وميزرا 
Mohammed Eid A Alotaibi

نجد أن تلك الشخصيات الثلاث مرتبطة فيما بينها، حيث قُدمت في الرواية بطريقة مباشر وغير مباشرة، فقد قدمها الراوي على لسان "راندلي" الذي أفصح عن بعض صفاتها. "الرجلان اللذان أعنيهما من نوع آخر، الأول قصير، والثاني طويل أبيض الشعر، المرأة جميلة. . جميلة جدا" (منيف،1990 ص46). حيث يقصد بالرجل القصير "عبّاس"، وبالرجل الطويل

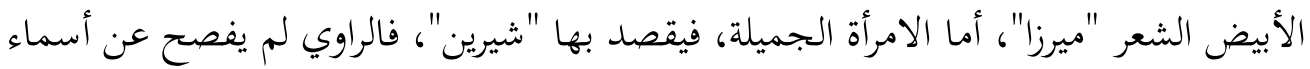
الشخصيات، حيث لم يذكر من صفاتها إلا صفة واحدة فقط، ليحفّز عند المتلقي عنصر برك التشويق والإثارة؛ للبحث عن صفاتها الأخرى، حتى ترتسم في ذهنية صورها كاملة. ثم نجد الراوي يقدم شخصية "عبّاس" دون أن يصرح باسمها، مكتفيا بذكر بعض صفاتها الدال عليها. "كان الرجل القصير، والذي يحمل عكازا، مثلما قدر بيتر تماما؛ كان وجهه يحمل مقدارا كبيرا من الغموض والعنف. فإذا بدأ يتحدث يمتلئ ذلك الوجه بالتجاعيد ... أما العينان فتنفتحان بطريقة آلية مثيرة ربما من الدهشة أو المرض أو من شيء آخر ينغل في الداخل" (منيف،1990 ص56). فبعد أن ذكر الراوي صفات الشخصية، يترك القارئ دون أن يخبره من

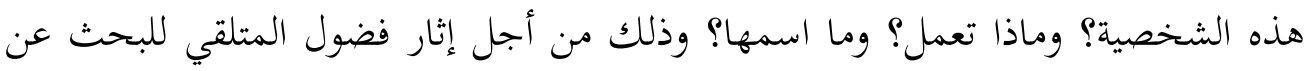
صفاتها الأخرى، وذلك لجعله أكثر الاتصاقا بأحداث الرواية حتى نهايتها. ثم نجد السارد بيتر يقدم بعض صفات شخصية المرأة شيرين: "بدت طويلة قليلا، أطول من باتريشيا، أما

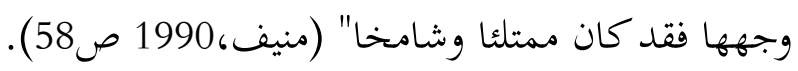

نلاحظ أن الراوي بعد ذكر صفاتها الخارجية، يتخلى عن تقديم أسمائها، ليسندها

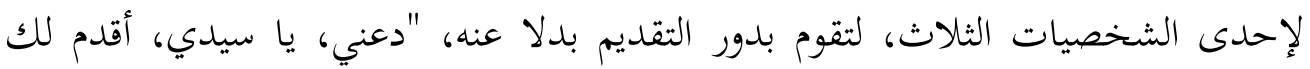

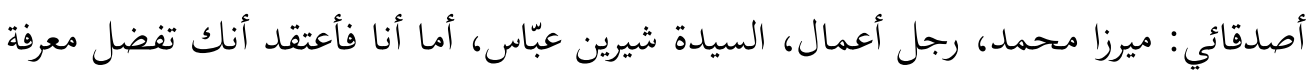
الاسم الأسهل: عبّاس، أما اسمي كاملا فهو رضا صفراوي عبّاس، وأصدقائي ينادونني عبّاس!"(منيف،1990 ص60). وبعد تسلسل الأحداث الروائية، نجد أن تلك الشخصيات بدت تظهر ملامحها وصفاتها بصور أكبر للقارئ، فقد عمد الراوي أيضا إلى الإفصاح عن

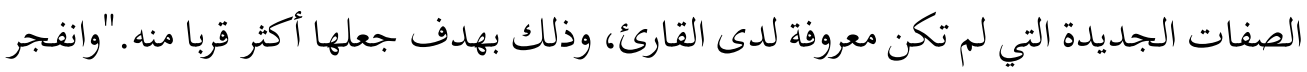


Mohammed Eid A Alotaibi

وجه عبّاس. كان وجها قميئا متداخل المعالم؛ أنفه كبير وكذلك شفته السفلى، أما عيناه فلم يستطع أن يميز لونهما، ولكنهما كانتا عينين متعبتين، ورقبته، رغم ضخامتها، كانت سريعة وكان

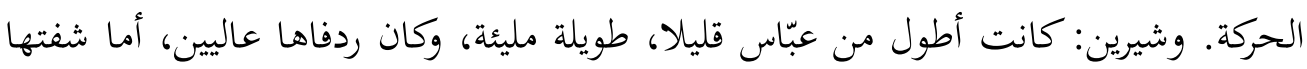
السفلى فقد كانت تسلية لذيذة لها طوال الفترة التي قضاها معظم. كانت تحرك الشفة، تمصها، تتركها تنهدل بانسياب، تزمها بنزق، لكنها في كل حركة كانت تدرك أنها تفعل ذلك بإثارة فيها مزيج من الشهوة والتحدي، وميرزا، إنه طفل كبير، يضحك بصخب، يحرك رأسه أكثر

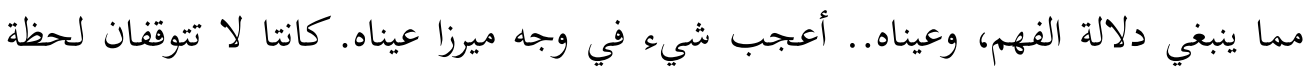

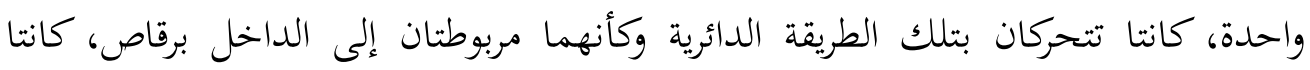
تتأرجحان، تركضان بلا توقف وبلا هدوء، وحين يوجه إليه سؤال تخف حركة العينين لحظة

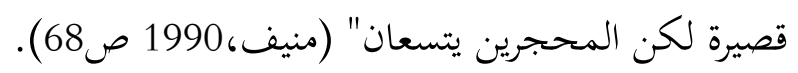

وبعد هذا التقديم المباشر لتلك الشخصيات، يترك الراوي مهمة البحث عن صفاتها إلى لى

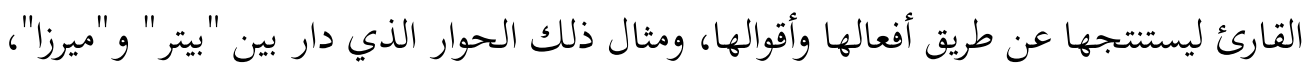
عرف القارئ أنه ضابط مخابرات، وهذا ما أثنار استغرابه، بعدما عرف سابقا من خلال الأحداث أنه رجل أعمال، فلماذا لم يفصح الراوي عن ذلك من قبل؟ ولماذا أخبر عنها هنا بالتحديد؟ كما اكتشف القارئ أن شخصية "عبّاس" تتصف بالعصبية والغضب، وذلك من خلال ردود أفعالهها التي برزت في أثناء خلافها مع "ميرزا". أما "شيرين" تلك القطة النزقة -

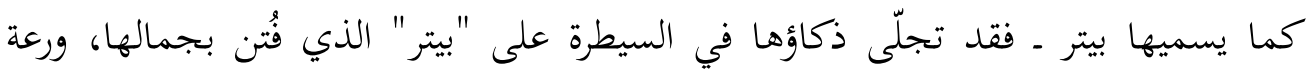
أسلوبها، فهي امرأة جميلة بما تحمله الكلمة من معنى. يمكن القول إن الكاتب عمد إلى استخدام الطريقتين في تقديم شخصياته الروائية، معتمدا على الراوي في توظيف تلك التقنية، حيث لم يقدمها بطريقة مباشرة، بل قام بإخفاء بعض صفاتها، دون أن يصرح بها بصورة كاملة، لذلك نجده يسند مهمة الكشف عنها لفهي للقارئ،

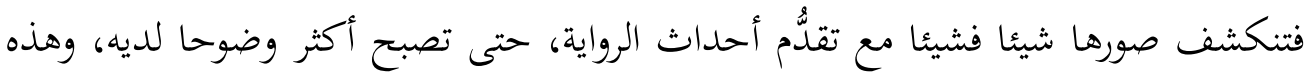
الطريقة تتسم بأنها أكثر توافقا بين صفات الشصخيات فئنات وأفعالها داخل العالم الروائي، مقارنة 
Mohammed Eid A Alotaibi

بالطريقة المباشرة الجاهزة التي تكون قابلة للتصديق أو التكذيب. كما نلاحظ أن الراوي ركّز على بعض صفات الشخصية التي تخدم أحداث الرواية، وذلك ما نجده في شخصية "شيرين" عندما اهتّم بذكر صفاتها الأنثوية، كنعومة جسدها، وعذوبة كلامها الذي يحرك الجماد، فكيف بالإنسان الذي يحمل مشاعر وأحاسيس مرهفة؟! لإقناع المتلقي بالأسباب التي جعلت

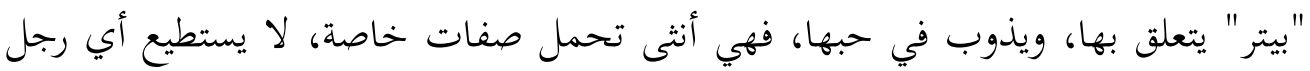
الانفلات من جمالها الساحر، وجاذبيتها الأخّاذة، ما أعطى النص قيمة جمالية وفنية خاصة.

أبعاد الشخصية: البعد الجسمي

يعد الاهتمام بالشكل الخارجي للشخصية (من حيث الطول والقصر، والنحافة والبدانة، والجمال والقبح، ولون البشرة، والعينين والشعر، وملامح الوجه، والعمر، واللباس وكل ما يتعلق بمظهرها) جزءا مهما في بناء الشخصية الرئيسة؛ لأنه يسهم بصورة قوية في إقناع القارئ بواقعية الشخصية (عثمان، 1982م، صنو109). وهذا الأمر يسعى الروائيون إلى تحقيقه في أعمالهم الروائية، لكنهم يتفاوتون في مدى عنايتهم بالبعد الجسمي لشخصياتهم، فمنهم من يصفها وصفا طويلا ودقيقا، ومنهم من لا يميل إلى هذا الوصف الدقيق المستقصي ويكتفي بالإشارة

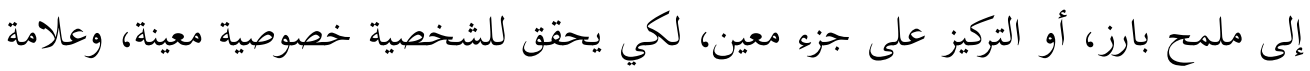
متفردة تميزها عن غيرها، وتذكرها بها كلما حضرت، ومنهم من لا يمنح هذا البعد أهميته

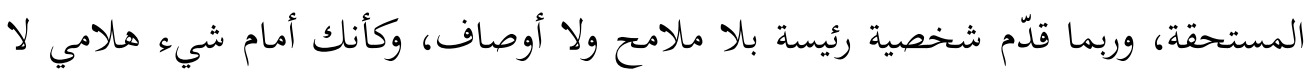
شكل له (الحازمي، 2009 ص219). لم تظهر الأبعاد الجسمية لشخصية "بيتر" إلا بصورة قليلة. مثل: أنه يلبس نظارات، وله

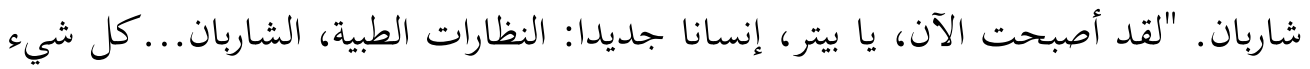
فيك تغير" (منيف،1990 ص43). ثم يذكر السارد أنه في منتصف العمر دون أن يحدده بصورة دقيقة، "صحيح أنه لم يعد شابا، لكنه لا يبدو كهلا أو مسنا" (منيف، 1990 ص52). ويبدو

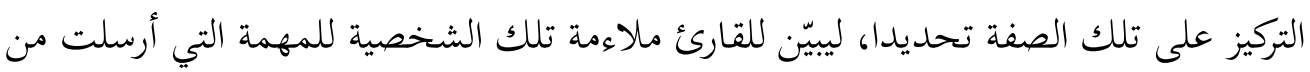

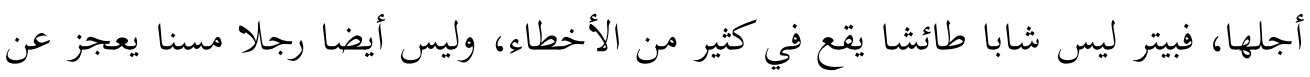


Mohammed Eid A Alotaibi

القيام بالمهام التي تتطلب الخفة في الحركة، والسرعة في الاستجابة، هي إذن شخصية فريدة من نوعها، تجمع بين عمر الشباب والقوة من جهة، والخبرة المهنية التي تؤهلها لتنفيذ المهمة المسندة إليها بصورة صحيحة من جهة أخرى.

نخلص مما سبق إلى أن الراوي لم يظهر البعد الجسمي للشخصية بطريقة واضحة، بل نجده يكتفي بذكر صفات محددة لها، مثل أن لها شاربين، وفي منتصف عمرها. أما بقية الأبعاد الجسمية فقد ظلت غامضة وغير معروفة لدى المتلقي.أما شخصية عبّاس مثلا، فنجد أن الراوي أخبر عن بعدها الجسمي بالاعتماد على طريقة الاخبار من خلال تقنية الوصف.

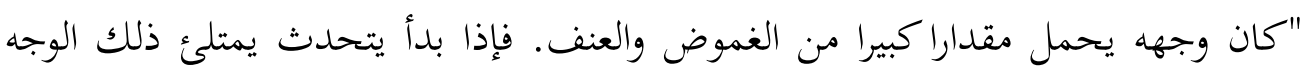

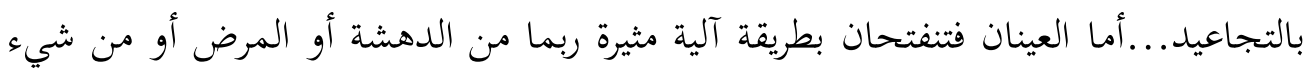
آخر ينغل في الداخل" (منيف،1990 ص56). "وانفجر وجه عبّاس. كان وجها قميئا متداخل المعالم؛ أنفه كبير وكذلك شفته السفلى، أما عيناه فلم يستطع أن يميز لونهما، ولكنهما كانتا

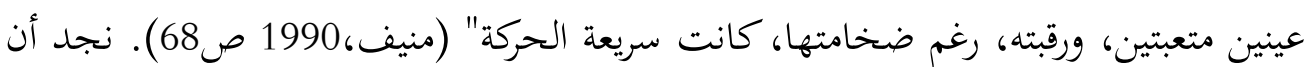
الراوي قد ركّز على البعد الجسمي لشخصية "عبّاس" بصورة واضحة، فهي ذات (وجه قميء متداخل المعالم، وأنفه وشفته السفلى كبير، وعينيه متعبتين، ورقبته ضخمة وسريعة الحركة)، فقد صوّر الراوي تلك الشخصية تصويراكاملا، يوضح ملامحها الخارجية التي يمكن للقارئ أن يتخيل صفاتها الجسمية. نلخص إلى أن أسلوب الإخبار، هو الأسلوب المستخدم في تقديم البعد الجسمي، وذلك من خلال الوصف الذي يعد التقنية الأنسب لتقديم الصفات الخَلْقية، والملامح الجسدية، فهناك صفات شخصية قد يتعذر تقديمها بطريقة أخرى غير

$$
\text { تقنية الوصف (الحازمي، } 2009 \text { ص230). }
$$

البعد النفسي

يعد البعد النفسي ثمرة البعدين الجسمي والاجتماعية في الاستعداد والسلوك، الرغبات والآمال، والعزيمة، والفكر، وكفاية الشخصية بالنسبة لهدفها. ويتبع ذلك المزاج: من انفعال

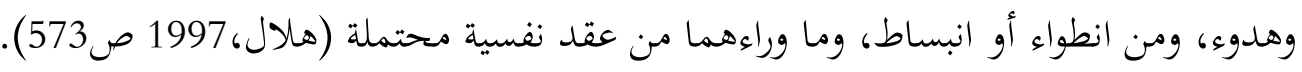


Mohammed Eid A Alotaibi

ويتميز الروائي بقدرته على تصوير أحوال الشخصية النفسية، وما تحمله من عواطف ومشاعر وطباع وأفكار، وما تحمله من انفعالات وأزمات نفسية، وهو إذ يفعل ذلك إنما يقدم البعد النفسي لشخصيته الروائية، التي يحرص، وهو يقدمها على جعلها شبيهة بالشخصيات الواقعية؛ لكي يقنع القارئ بواقعيتها (الحازمي، 2009 ص231).حيث تتألف الشخصية في تصوّر فرويد من ثلاثة جوانب: (الهو، والأنا، والأنا الأعلى)، وهذه الجوانب أو الأجهزة حين تعمل منسجمة صلهم تسهل للفرد طريقة التفاعل مع ذاته ومع بيئته، وإذا لم تكن منسجمة، فإنها تؤدي إلى صعوبة تكيف الفرد مع ذاته ومع بيئنه، مما يؤدي إلى الخلل في الشخصية. الجوانب النفسية للشخصية: الهو

الهو هو الواقع النفسي الحقيقي، وهو يمثل العالم الداخلي للتجربة الإنسانية الذاتية. فالهو

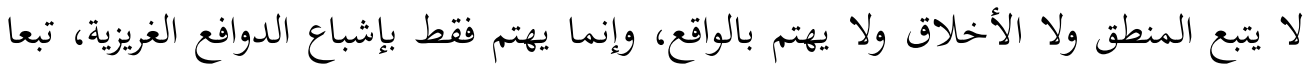

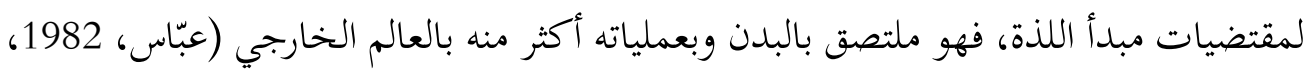

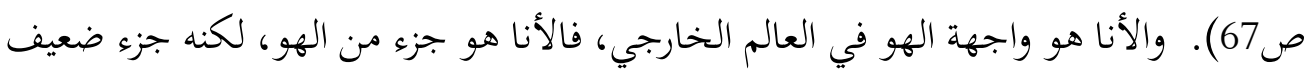

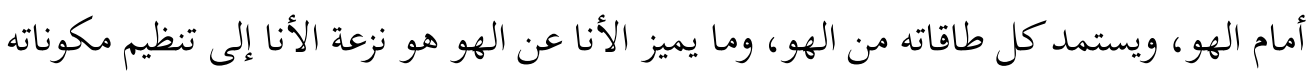

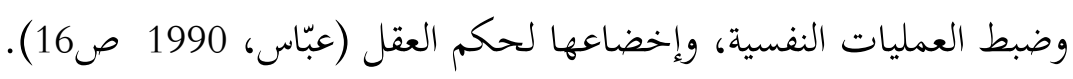

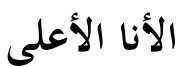

هو يمثل الجانب الخلقي من الشخصية، كما أنه يمثل الجانب المثالي بعكس الأنا الذي

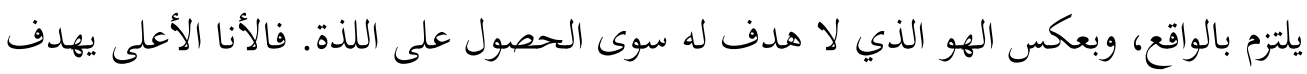
في ضبط وتنظيم النزعات التي من شأنها أن تعرض كيان المجتمع للخطر، إذا عبر عنها الفرد تعبيرا غير مقيد، وأهم هذه النزعات تتجلى في نزعات الجنس والعدوان (عبّاس، 1982 ص69). ويبدو هذا التقسيم الفرويدي ظاهرا في علاقة "بيتر" و "شيرين" في الرواية، "فيبتر" أتى من بريطانيا لأجل مهمة محددة، وهي القضاء على حكم العجوز والسيطرة على الموارد

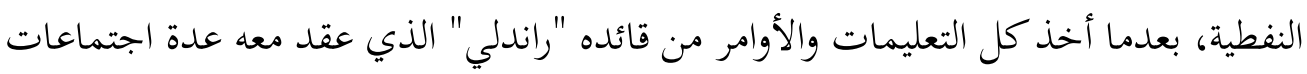
قبل سفره حول الخطط التي يجب تنفيذها، فعندما وصل "بيتر" إلى الشرق والتقى "بشيرين" 
Mohammed Eid A Alotaibi

بدأ التحوّل من كون "شيرين" أداة يمكن الاستفادة منها في المهمة المنوطة إليه إلى حب وغريزة جنسية، ما أدى إلى انجرافه نحوها، حتى كاد أن يبوح لها بكل أسرار مهمته الخاصة.

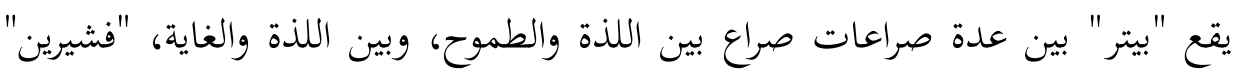

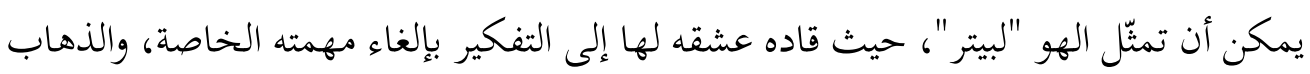

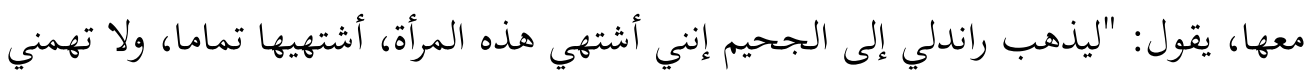
النتائج بعد ذلك.." (منيف،1990 ص163). ويقول أيضا: "آه ما أشد فتكها، أين تعلمت كل هذا الإغراء؟! وكيف تتقنه بهذه البراعة التي لا تعرف التوقف أو الخطأ؟! إن من هذه

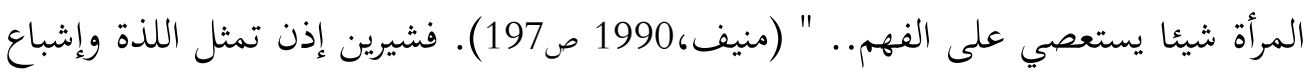
الغريزة عند "بيتر".

أما الأنا الضعيف أمام متطلبات الهو، فيبدو ظاهرا في موقفه من تلك العلاقة وطبيعتها.

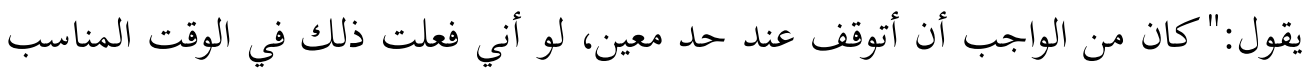

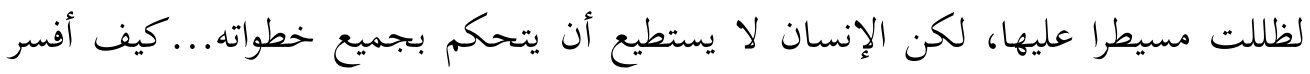

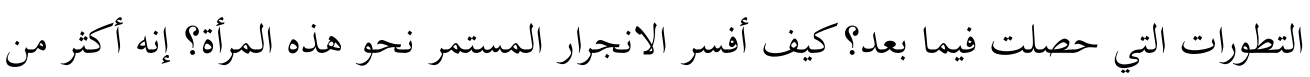

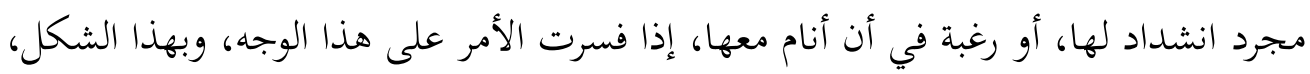

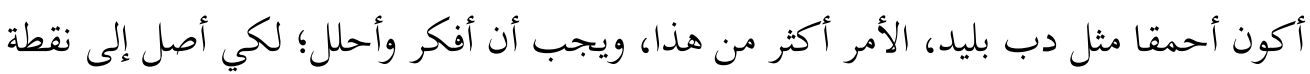

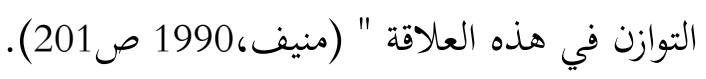

ظل الصراع القائم بين الأنا الضعيف، والهو الجامح نحو إشباع الدوافع الغريزية مستمرا، "رائحة جسدها فتاكة لا أعرف كيف تتسرب إليّ، وتخدرني تماما عشرات المرات قررت بيني

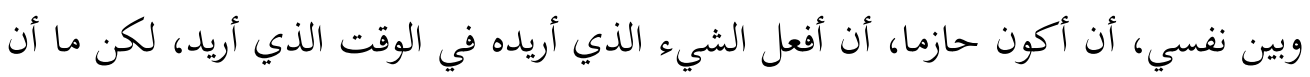

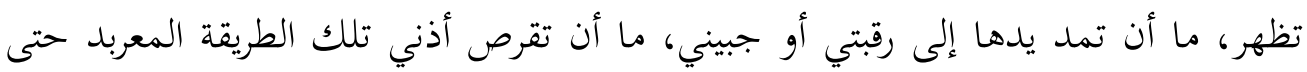

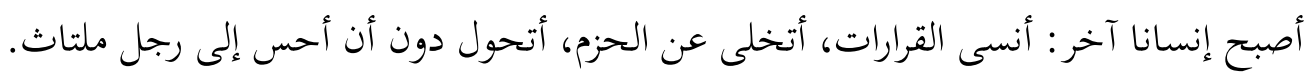
كل ما تريده، نعم كل ما تريده، لا أتردد لحظة واحدة في أن أستجيب له...." (منيف، 1990 
Mohammed Eid A Alotaibi

يتضح من كلام "بيتر" أنه وقع بين نزعتين، نزعة تقوده نحو تحقيق رغباته الغريزية وميوله

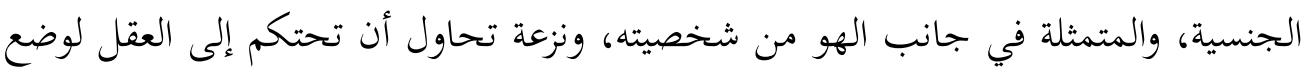
حدا لتلك العلاقة، والمتمثلة في جانب الأنا الضعيف من شخصيته، فمشاعره الداخلية تميل -غالبا- لتحقيق غرائزه الجنسية. أما الأنا الأعلى المتمثل في السلطة، فيظهر - كما يبدو في تعليمات "راندلي" التي ظلت دائما عالقة في ذهنه، يتذكرها عندما يرى نفسه خارجا عنها، وكأنها بمثابة جرس إنذار تخبره أنه خالفها، أو بمثابة الضمير الحي المثالي الذي يجب أن يحتذى به، فنجد الأنا الأعلى يحضر عندما تضعف نفسه أمام غرائزه ونزواته، ليأمره بالتوقف، بلفي

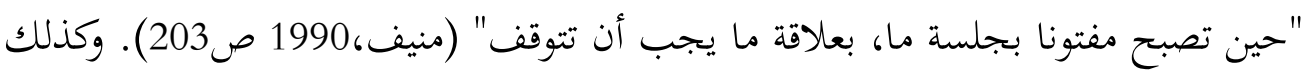
يتذكر كلامه "حين تحس بانجذاب حقيقي نحو امرأة معينة يجب أن تتوقف يا بيتر؛ لأنك

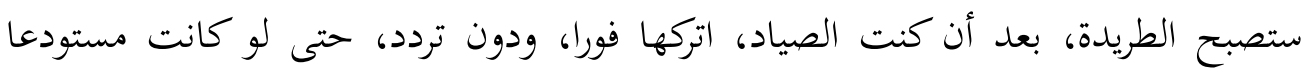

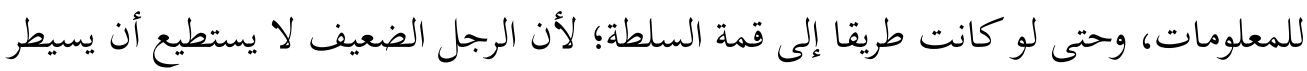
على امرأة قوية... هل فهمت؟؟" (منيف، وحتى 1990 ص206). إن الأنا الأعلى هنا تمثّل الجانب المثالي الذي رسمه له "راندلي"، إلا أن "بيتر" ظل صنل

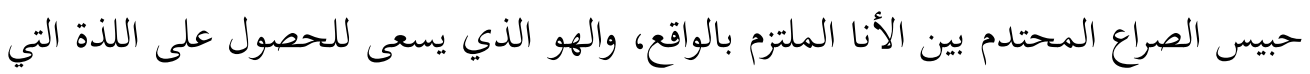
وجدها في جسد "شيرين"، فيتذكّر بياض بشرتها الذي يعكس مسيرة الدماء الراكضة تحت الجلد، ويلوّن شفافية البشرة، ليقول لنفسه بتأكيد أخرق: "هذه المرأة تفعل شيئا خارقا من بئن أجل أن تظل مشعة هكذا" (منيف،1990 ص208). ويقول لنفسه بغضب: "ليس عليّ إلا أن أكون حمارا أبلها يقف في الشمس الحارقة دون حركة. إذا أردت أن أنفذ تعليمات راندلي. هذا ما يريده راندلي... كأنه يتحدث عن أمور عادية، وبعد ذلك: بيتر افعل ...بيتر لا تفعل. ماذا يهم إذا كانت لي علاقة من هذا النوع مع هذه المرأة؟ أفهم ما يقصده، ما يحذر منه، لكن الأمر كله يتوقف عليّ. حتى لو كنت شديد الصلة بشيرين، وأرغب أن ألتقي بها دائما، فأنا شديد الانتباه في نفس الوقت، لا أقول إلا ما أريد قوله ولا أتصرف إلا بعد تفكير عميق

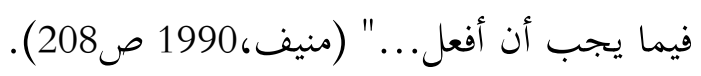


Mohammed Eid A Alotaibi

إذن "بيتر" تنتزع شخصيته جانبان، الجانب الأول: شخصية الهو التي تسعى وراء إشباع الرغبات وتحقيق اللذة الكامنة في جسد "شيرين". والجانب الثاني من شخصيته الأنا الذي يحاول السيطرة على جموح الهو ليضع حد له، ما أدى إلى الصراع بين الجانبين الهو والأنا.

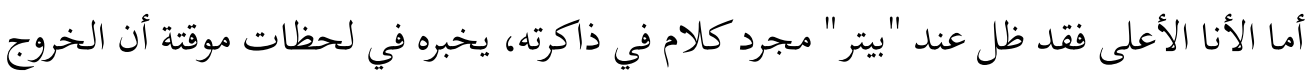
عن عن تعليمات "راندلي"، يؤدي إلى فشل مهمته التي جاء من أجلها، إلا أنه لا يخشى سيرى خطر الوقوع في ذلك المحذور. الجدول التوضيحي لجوانب النفسية لشخصية "بيتر" الهو
(الرغبة) رغبات "بيتر" المتمثلة في عقل "بيتر" ومحاولته في تعليمات "راندلي" التي

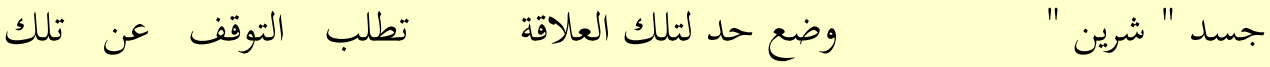
العلاقة
توقف

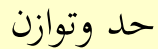
استمرار

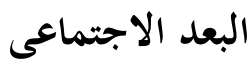

يتمثّل البعد الاجتماعي في انتماء الشخصية إلى الطبقة اجتماعية، في عمل الشخصية، وفي نوع العمل، ولياقته بطبقتها في الأصل، وكذلك في التعليم، وملابسات العصر وصلتها

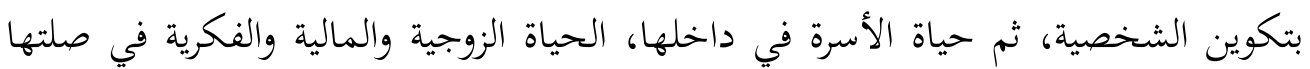
بالشخصية، ويتبع ذلك الدين والجنسية، والتيارات السياسية، والهوايات السائدة في إمكان تأثيرها في تكوين الشخصية (هلال، 1997 ص573). وقد سلك الروائيون في تقديم البعد الاجتماعي طريقتين: الطريقة الأولى: طريقة الإخبار، وهي تتجلّى بصورة مباشرة، والطريقة الثانية: طريقة الإظهار، وهي تتجلّى بصورة غير مباشرة، فهي تقوم على مبدأ التدرج الذي يكشف من خلاله التحولات التي تطرأ على الشخصية الروائية. 
Mohammed Eid A Alotaibi

ومن الشخصيات التي اعتمد الراوي في تقديم بعدها الاجتماعي على طريقة الإخبار شخصية أشرف آية الله."كان أشرف عنصرا فنيا، كما يحب أن يطلق على نفسه. يتقن ثلاث لغات، الإنكليزية والفرنسية والإسبانية، إضافة إلى إلمام واسع بالقضايا القانونية، ونتيجة دراسته في كلية لندن فقد كان للحياة الإنكليزية تأثير واضح على سلوكه وملابسه وطريقته في إلى إلى الحياة،... وكان بعد زواجه من فتاة مكسيكية بعيدا عن جو السياسة، بل ويكرهها؛ لأنه يعتبر "خدمة الوطن" في الاستقرار وسيادة القانون... أما بدأت الاضطرابات فقد فكر أن يغادر الوطن نهائيا، لكن صلة القرابة التي تربطه بعبّاس، وشعور الامتنان الذي يكنه له، بعد أن

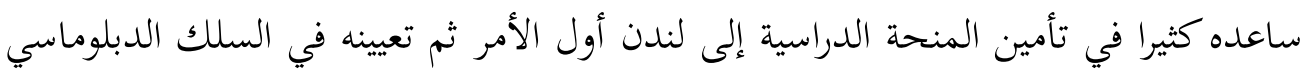
بعد ذلك جعله يوافق على البقاء" (منيف، 1990 ص87 ـ 88).

ففي أول لقاء بين القارئ والشخصية، يقدم الراوي معلومات حول شخصية أشرف عن طريق الإخبار بأن لها صلة قرابة تربطه بعبّاس، وشعور الامتنان الذي يكنه له بعد أن ساعده في تأمين منحة دراسية في لندن، ثم تعيينه في السلك الدبلوماسي، إلى جانب إتقانه ثلاث لغات، اللغة الإنكليزية، واللغة الفرنسية، واللغة الإسبانية، كما عرف القارئ أيضا أثر الحياة الإنكليزية على سلوكه، وملابسها، وتأثير زواجه من الفتاة المكسيكية على عمله السياسي. ومن النماذج أيضا التي يظهر فيها البعد الاجتماعي في الرواية، تصوير الحياة الاجتماعية في القرية " فإذا وصلت إلى الميناء الصغير، في الناحية الشمالية في القرية، أجد الصيادين وقد عادوا من رحلة الليل وبدأوا بإنزال شباكهم وصيدهم، وهم بحركاتهم الموزونة، ونظراتهم المتعبة، يبدون شديدي الحذر وربما الخوف، خاصة حين يتزاحمون في النزول، وكل واحد يريد الانتهاء

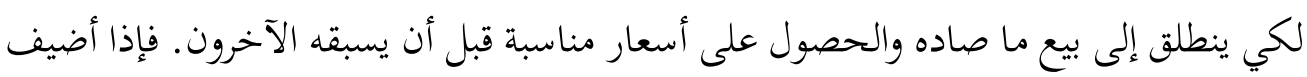
على ذلك وجود الصبية الذين يريدون الحصول على شيء ما، على سمكة نسيها أحد الصيادين أو على قطعة خشب، والمتطفلون من الكبار الذين يهمهم أن يعرفوا حالة الصيد في ذلك لك اليوم، والأسئلة التي يوجهونها عن الرياح والبحر، ثم المساومات الشاقة التي يجرونها حول ئرل

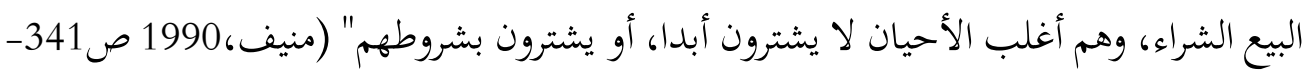


Mohammed Eid A Alotaibi

342). يتضح من خلال هذا المقطع السابق اعتماد الراوي على طريقة الإخبار في تقديم البعد الاجتماعي، حيث صوّر الحياة الاجتماعية في القرية، وكيفية العيش فيها، فسكان القرية

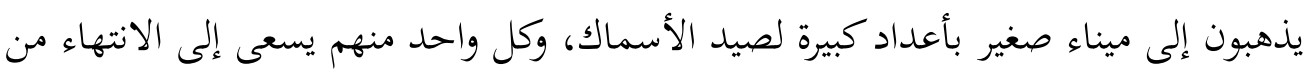

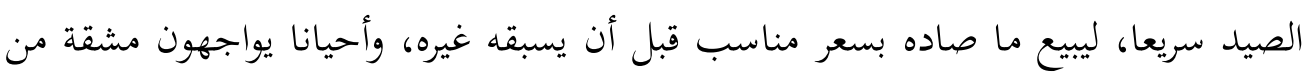
قبل التجار في شراء ذلك السمك، ويتضح هنا بجلاء معاناة سكان القرى في البحث عن لقمة العيث.

الراوي والشخصية

يصنّف الراوي بحسب موقعه من النص إلى نوعين: الراوي الخارجي، وهو الذي يصف

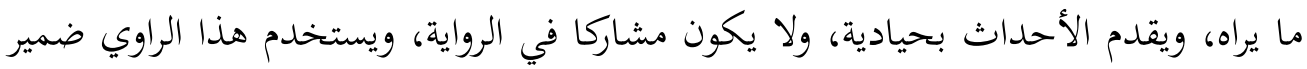
الغائب، ويسمى "بالراوي العليم" الذي يوصف بأنه يمتلك قدرة غير محدودة لكشف الأبعاد الداخلية والخارجية للشخصيات. أما إذا كان محدود الرؤية، أي أنه ينظر من خلال ما تراه الشخصية، فإن حريته تنحصر، ليصبح متساويا مع الراوي الداخلي، الذي يعرف بأنه يكون

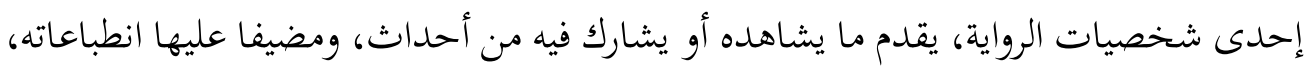
ووجهة نظره ويسمى هذا الراوي بـ "الراوي المشارك، أو الرواي المصاحب"، ويستخدم ضمير

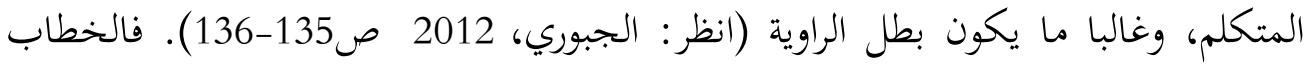
الروائي في جوهره مرتبط بالعلاقة بين الراوي والشخصية؛ لأنه في حقيقته نقل لأقوالهم وأفكارهم وأفعالهم بواسطة الراوي (الحازمي، 2009 صروفي فريط 614)، وبناء على قربه أو بعده من الشخصيات

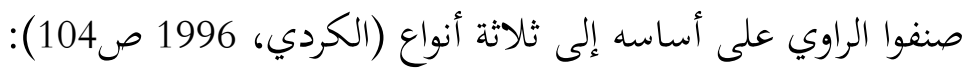

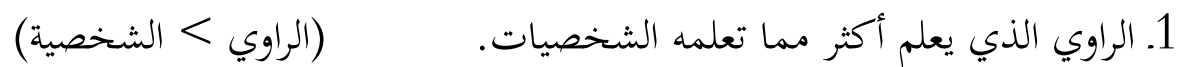
2. الراوي الذي لا يعلم إلا ما تعلمه الشخصيات. الراوي = الشخصية) 3. الراوي الذي يعلم أقل مما تعلمه الشخصيات. الراوي > الشخصية) ففي الرواية نجد أن الكاتب اختار الجمع بين الراويين -الراوي الخارجي والراوي الداخلي -

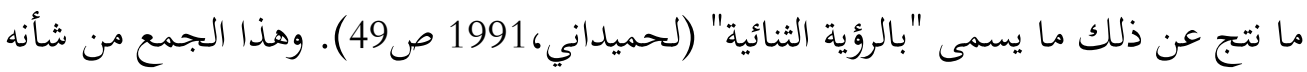


Mohammed Eid A Alotaibi

أن يبرز الجوانب المختلفة للحقيقة، ويكسر حدة السلطة المطلقة التي يحتكرها الراوي المفرد المهيمن على القص (الكردي، 1996 ص140). ومن النماذج التي ظهر فيها الراوي الخارجي

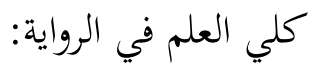

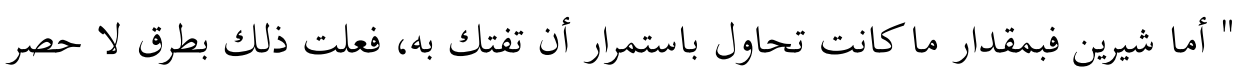
لها، حتى اعتبر بيتر أن كل حركة من حركاتها تمزيق لمقاومته أو تردده" (منيف، 1990 ص201). فالراوي هنا - كما يبدو - يعلم أكثر مما تعلمه الشخصية، فبيتر لا يعلم ما يدور في تهري مخيلة شيرين، ولا يعلم ما هو الشيء الذي تنوي عليه، فهو يقف أمام تلك الحركات المغرية

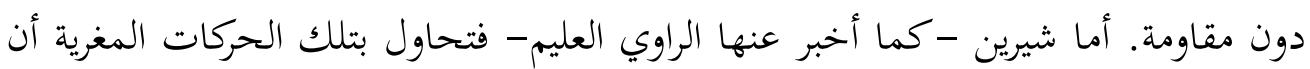
تفتك ببيتر، وتسيطر على مشاعره.

وفي مقطع آخر من الرواية نجد أن الراوي أصبح محدود العلم مقيد الحرية، مساويا للراوي الداخلي، "شعر بيتر ماكدونالد أنه وسط رجال يريدون أن يقتحموه دفعة واحدة، أن يسلبوه كل طاقته على التصرف السهل المباشر، ورغب من أعماق نفسه أن يرد عليهم دفعة واحدة،

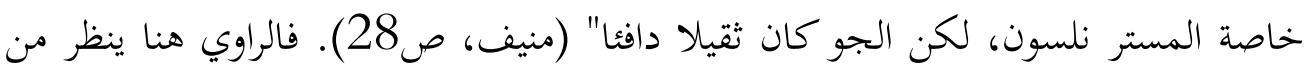
خلال عيني شخصية بيتر، فهو يشعر مثل ما يشعر به، ويحس مثل ما يحس به، فلا يعلم ما يدور في شخصيتي الرجلين، ولا يعلم بماذا يفكران؟ ولا يستطيع أن يعلم ما يدور في مخيلتهما، فالراوي هنا أصبح مجرد شاهد على الأحداث الروائية.

وبعد ذلك نجد الراوي في الرواية يتحول من الراوي الخارجي إلى الراوي الداخلي، فينتقل من الضمير الغائب الذي يقتضي الرؤية الموضوعية، إلى الضمير المتكلم الذي يقتضي الرؤية

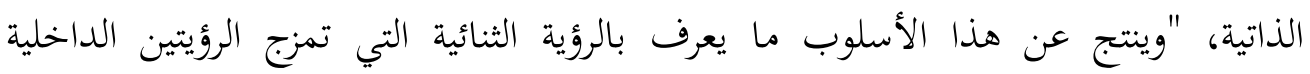
والخارجية" (الحازمي، 2009 ص620). نلاحظ أن الكاتب في الرواية، لم يسند تلك المهمة للشخصية أن تقوم بدور الراوي، إلا بعد أن بناها ثقافيا ومعرفيا، حتى أصبحت على درجة درجة

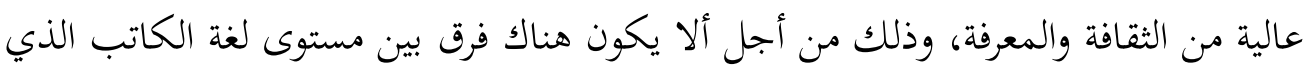
يقف خلف الراوي الخارجي، ومستوى لغة الشخصية التي تقوم بدور الراوي الداخلي، ونلمح 
Mohammed Eid A Alotaibi

هذا الانتقال من الراوي الخارجي إلى الراوي الداخلي في المقطع التالي: "منذ اللحظة الأولى لوصولي إلى هذه المدينة الملعونة والدنيا تغلي، المظاهرات لم تتوقف إلا لتبدأ من جديد،

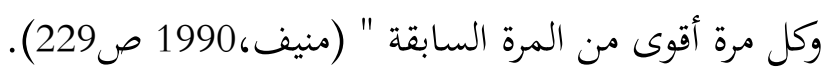
هكذا نجد أن الراوي باستخدامه ضمير المتكلم، يجذب القارئ، ويعقد صلة معه بصورة مباشرة، من أجل استثارت عاطفته، ودفعه للالنصاق بأحداث الرواية بصورة أكثر حميمة، وهو ما نلاحظه في المقطع السابق، حيث نجده يحاول أن يلفت انتباه القارئ اتجاهه، فبعد وصوله إلى تلك المدينة التي ينعتها بالملعونة، وجد المظاهرات لا تحقق مبتاغه الذي يريده،

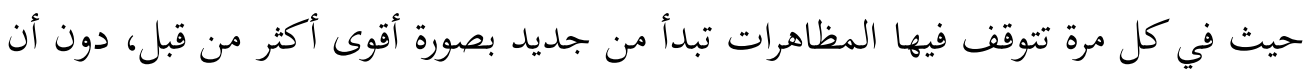
يسقط حكم العجوز، وذلك ليبيّن للمتلقي مدى صعوبة المهمة المكلف بها "بيتر". الراوي بين الظهور والغياب: الراوي الظاهر

هو الراوي الذي يعلو صوته على جميع الأصوات، فلا تسمع إلا صوته، ولا تعلم إلا ما

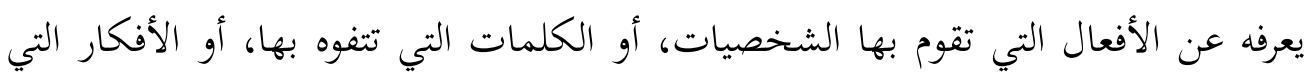

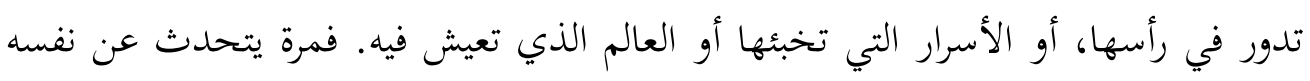
بضمير المتكلم معبار عن موقعه بصراحة، ومرة أخرى يتحدث بضمير الغائب مبرزا تفاصيل

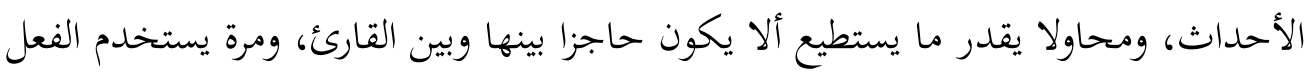

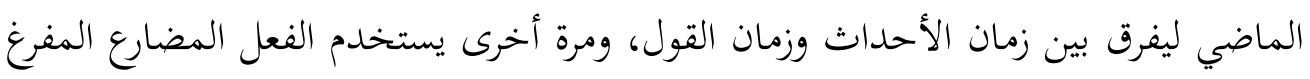

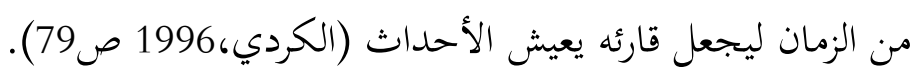
ومن الأمثلة على الراوي الظاهر في الرواية: " حين رن جرس الهاتف في في الغردئ الغرفة المجاورة

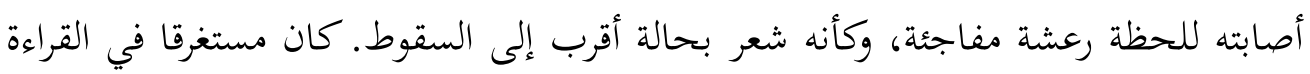

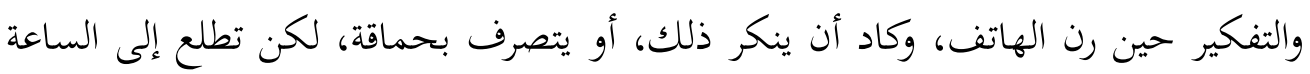
وهو في طريقه إلى الهاتف. كانت السابعة تماما وأدرك أنهم جاؤوا" (منيف، 1990 ص26). ففي هذا المقطع نلاحظ علو صوت الراوي على صوت الشخصية، فليس هناك صوت إلا صوته، ولا حديث إلا بلسانه، وبذلك يسلب الشخصية الروائية حرية حوارها مع نفسها، 
Mohammed Eid A Alotaibi

والإيهام بواقعيتها، حيث هدم جسور التواصل المباشر مع المتلقي، من خلال تنصيب نفسه الوسيط بين الشخصية وقرائها. الراوي غير الظاهر أو الخفي

هو الراوي الذي يختفي، ويجعل القارئ أمام الشخصيات التي تبرز صورتها من خلال

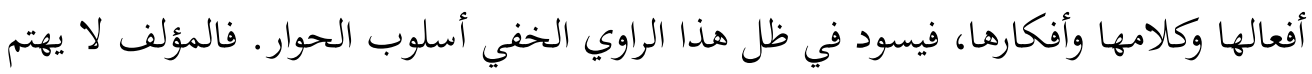
بإبراز العلامات الدالة على صورته أو صوته أو لهجته، بل يكتفي بمجرد تحديد الموقع الذي ترصد منه الأحداث والأقوال والأفكار، واتجاه الكاميرا الراصدة، والمسافة التي تفصل بينها وبين الأحداث المرصودة. وقد اختلفت تسميات النقاد لهذا النوع من الرواة، فأطلقوا عليه حينا " العاكس"، وحينا آخر "الكاميرا"، وحينا ثالثا "المرآة"، وغير ذلك من الأسماء المقتبسة

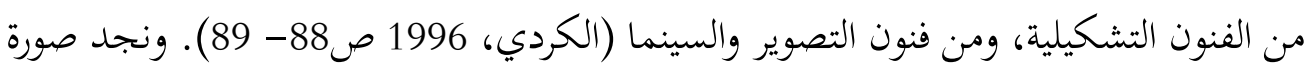
هذا الراوي في الحوار الذي دار بين الشخصيات في الرواية، ومن النماذج الدالة عليه:

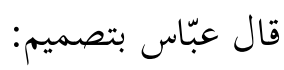

ـ يجب أن أجد الشموع، لا يمكن أن نبقى هكذا في الظلمة.

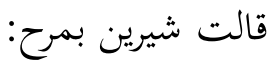

ـ افترض نفسك في المسرح، قبل رفع الستارة، ألم تحس بجمال تلك اللحظات يا عبّاس؟

$$
\begin{aligned}
& \text { ـ وهل تريديننا أن نمثل الآن؟ } \\
& \text { ـ لا أدري، ولكن يجب أن نمثل. }
\end{aligned}
$$

وصممت لحظة، ثم سألت بنفس الطريقة المرحة: ـ ماذا تقترح يا مستر ماكدونالد؟ سأل بيتر بكآبة: - n ـ ماذا أقترح؟ ماذا تعنين؟

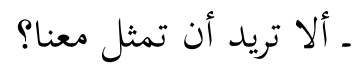
رد بيتر بانفعال وسرعة وهو يحس يدها تضغظ: 
Mohammed Eid A Alotaibi

$$
\text { ـ بالتأكيد ... بالتأكيد سوف أمثل معكم ... (منيف، } 1990 \text { ص199- 200). }
$$
ثم يستمر الحوار بين شيرين وبيتر وعبّاس، ولا يتدخل الراوي إلا في مواطن قليلة، ليشرح

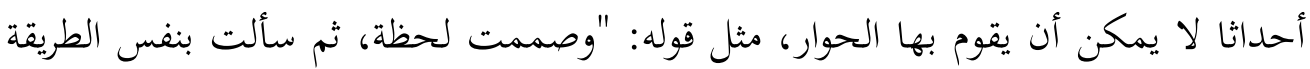

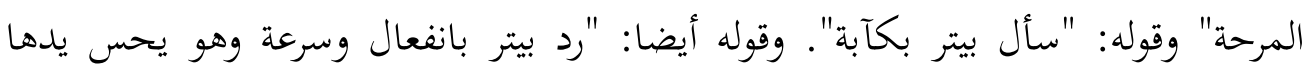

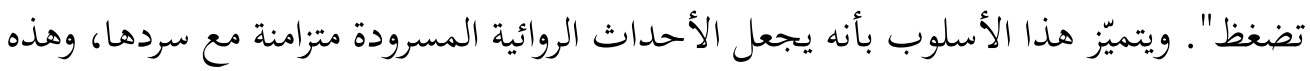
ميزة الحوار، الذي يعمل على الحضور الذهني والنفسي للشخصيات، ويتيح لها فرصة الكلام

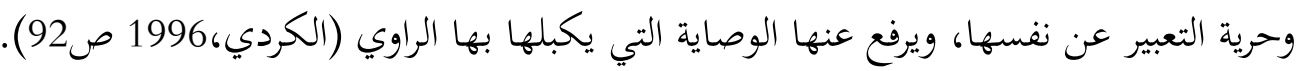
حيث إن ظهور الراوي المبالغ فيه، قد يحيل الرواية إلى تقرير سردي أو خطبة، أما اختفاؤه

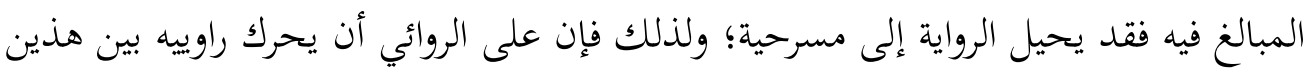

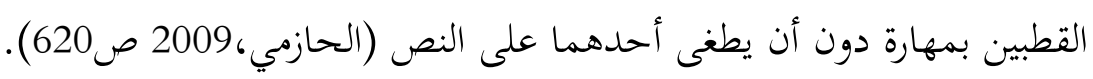

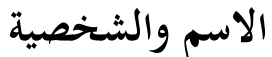

يسعى الروائي وهو يضع الأسماء لشخصياته أن تكون متناسبة ومنسجمة، بحيث تحقق للنص مقروئيته وللشخصية احتماليتها ووجودها، فمعظم المحللين البنيويين للخطاب الروائي قد أصروا على أهمية إرفاق الشخصية باسم يميزها ويعطيها بعدها الدلالي الخاص، وتعليل

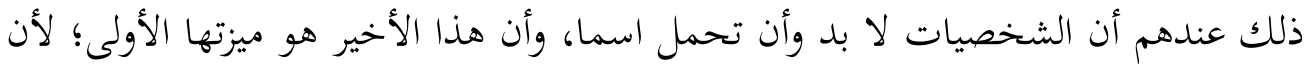
الاسم هو الذي يعين الشخصية ويجعلها معروفة وفردية. وقد يرد الاسم الشخصي مصحوبا بلقب يميزه عن الآخرين الذين يشتركون معه في الاسم نفسه، كما يزيد في تحديد التراتب الاجتماعي للشخصية الذي تخبرنا عنه المعلومات حول الثروة أو درجة الفقر (بحراوي، 2009 ص 247-248). ويتراوح استخدام الروائيين لأسماء شخصياتهم الحكائية بين مستويين تعبيريين (بحراوي، 2009 ص92):

أ- مستوى اعتباطي: يخلو معه الاسم من أي دلالة. ب- مستوى رمزي: يكون معه الاسم زاخرا بالدلالات المعبرة عن السمات المميزة للشخصية. 
Mohammed Eid A Alotaibi

وقد اهتم الروائي عبد الرحمن منيف، بعلاقة الاسم بالشخصية في معظم شخصياته الروائية، حيث نجد معظمها لها دلالات موحية، تظهر من خلال دورها واتجاهها، وتنعقد الصلة بين مدلول اسم الشخصية، ومجريات أحداث الرواية، ومن تلك الأسماء التي كان لها دلالات واضحة:

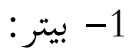

جاء اسم "بيتر" في القواميس بمعنى "التلاشي" (البعلبكي، 1998 ص678). ولو رجعنا إلى دور "بيتر" في الرواية، لوجدنا أن الاسم اختير بعناية من قبل الكاتب، حيث جرت بـ أحداث

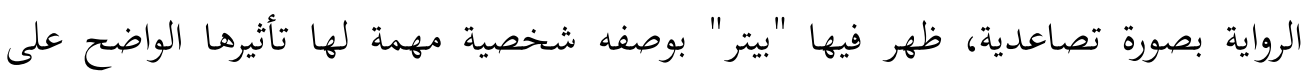
الشخصيات الأخرى، وفي نهاية أحداث الرواية تتلاشى أهميتها، بعدما كان لها الدور البارز في تلك المهمة السياسية، وهي إسقاط حكم العجوز، حيث وجدت أن كل ما ما صنعته طيلة الفترة الماضية، ذهب أدراج الرياح، بعدما كسب الأمريكان السباق، وأصبح لهم الكلمة العليا،

$$
\text { 2- والسيادة في الشرق. }
$$

يقصد باسم شرين - كما جاء في قاموس (كنز لغات) - بالشيء الحلو والعذب الطيب

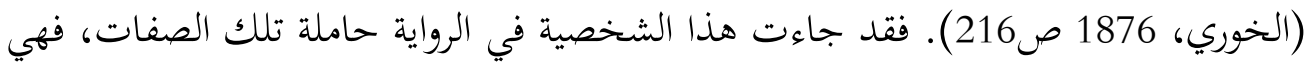
امرأة فاتنة بجمالها، ساحرة بكلامها، فقد جاء وصفها على لسان بيتر "وشيرين: كانت أطول من عبّاس قليلا، طويلة مليئة، وكان ردفاها عاليين، أما شفتها السفلى فقد كانت تسلية لذيذة لها طوال الفترة التي قضاها معهم. كانت تحرك الشفة، تمصها، تتركها تنهدل بانسياب، تزمها بنزق، لكنها في كل حركة كانت تدرك أنها تفعل ذلك بإثارة فيها مزيج من الشهوة والتحدي" (منيف،1990 ص68). فقد ملكت بتلك الصفات الأنثوية الفاتنة قلب "بيتر" حتى فكر في أكثر من مرة أن يترك المهمة التي جاء من أجلها، "ليذهب راندلي إلى الجحيم إنني أشتهي

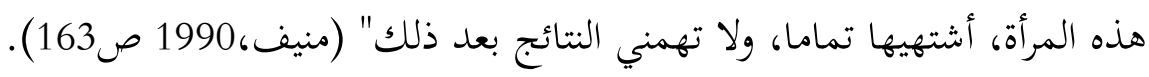
3- 3 - مبّاس: 
Mohammed Eid A Alotaibi

يراد باسم عبّاس تقطيب ما بين العينين (ابن منظور،1993 ج1: ص128)، ما يدل على أن تلك الشخصية تتصف بأنها سريع الغضب والانفعال. " كان وجهه يحمل مقدارا كبيرا من الغموض والعنف. فإذا بدأ يتحدث يمتلئ ذلك الوجه بالتجاعيد" (منيف، بال، 1990 ص56). فقد

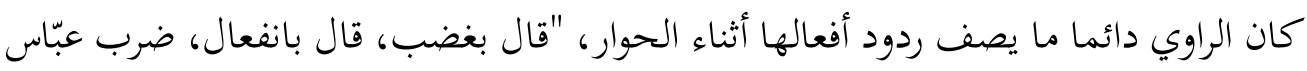
الطاولة بيده وقال بغضب، استشاظ عبّاس غضبا". وهذه الصفات سواء كانت عن طريق الإخبار أو عن طريق الإظهار، تدل على أن الكاتب لم يكن اختياره لاسم الشخصية اعتباطيا. وفي المقابل نجد أن هناك أسماء شخصيات في الرواية، يخلو اسمها من أي علاقة دلالية،

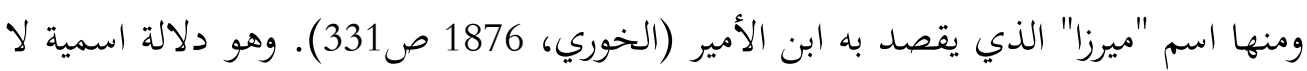

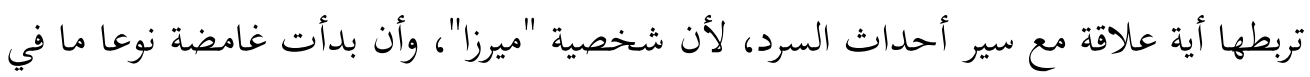
الرواية، إلى جانب صفاتها الأخرى، لا يتضح أي صلة بين اسمها ومجريات الأحداث الروائية المسرودة.

\section{الشخصية ونموذج غريماس العاملي}

حاول غريماس بعدما استفاد من الأبحاث الشكلانية التي تناولت الحكايات العجيبة،

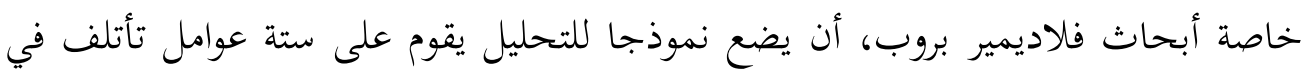
ثلاث علاقات (لحيمداني، 1991 ص 33-36): 1 - علاقة الرغبة: تجمع هذه العلاقة بين من يرغب "الذات"، وما هو مرغوب فيه

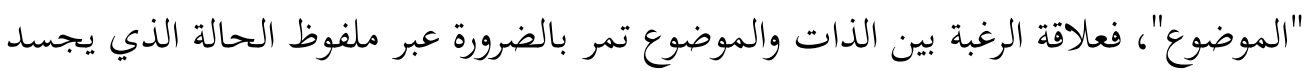
الاتصال أو الانفصال، كما تمر بعد ذلك عبر الملفوظ الإنجاز الذي يجسد تحولا اتصاليا أو انفصاليا.

r- علاقة التواصل: إن فهم علاقة التواصل ضمن بنية الحكي ووظيفة العوامل يفرض

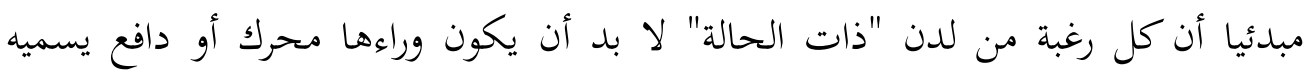
"غريماس" مرسلا، كما أن تحقيق الرغبة لا يكون ذاتيا بطريقة مطلقة، ولكنه يكون موجها 
Mohammed Eid A Alotaibi

أيضا إلى عامل آخر يسمى مرسلا إليه، وعلاقة التواصل بين المرسل والمرسل إليه تمر بالضرورة عبر علاقة الرغبة أي عبر علاقة الذات بالموضوع. r- علاقة الصراع: ينتج عن هذه العلاقة إما منع حصول علاقة الرغبة وعلاقة التواصل،

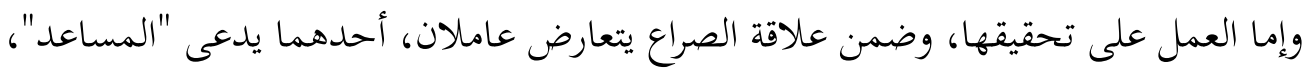
والآخر "المعارض"، فالأول يقف بجانب الذات، أما الثاني فيعمل على عرقلة جهودها من أجل الحصول على الموضوع. تدور أحداث رواية "سباق المسافات الطويلة" حول إرسال

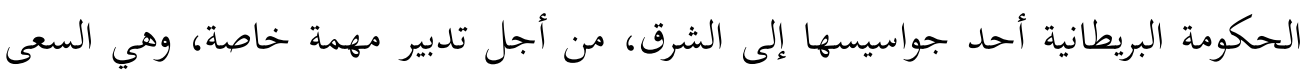
لقلب الحكم، وإسقاط العجوز، من أجل السماح بدخول النفوذ البريطاني في تلك الدولة، ومن ثم السيطرة على مواردها النفطية.

ولو أخذنا نموذج "غريماس" وطبقناه على رواية سباق المسافات الطويلة، لوجدنا أن "بيتر" يمثل الذات، التي تسعى إلى تحقيق موضوع القيمة بوصفها مرسلا، من خلال إقامة

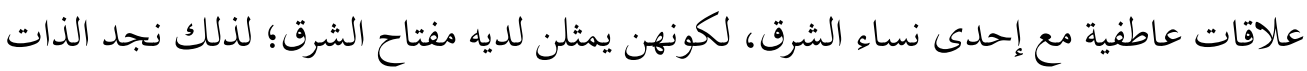

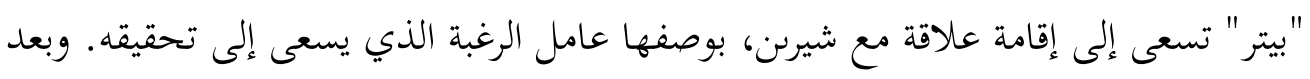

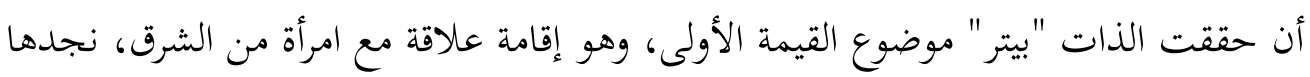

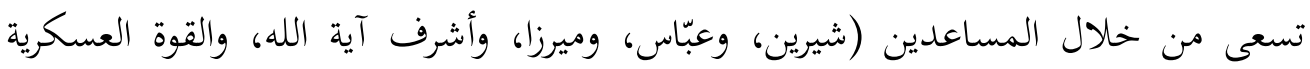

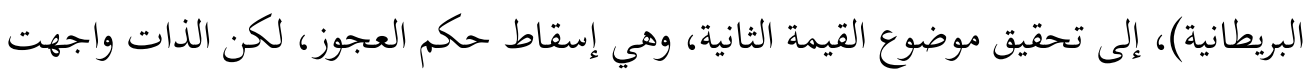
خصوما تحاول أن تعيق تنفيذ مهمتها التي تطمح لتحقيقها، وهؤلاء الخصوم هم: العجوز

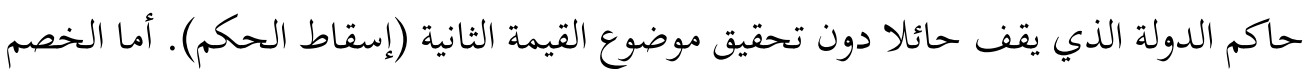
الثاني فيمكن أن نسميه بالخصم الخفي الذي يظهر وجهه الحسن، ويبطن وجهه القبيح، وهذا

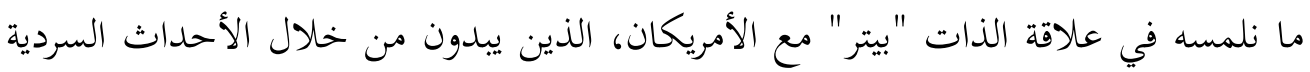
وكأنهم أصدقاء أوفياء، يتظاهرون الوقوف إلى جانبه، إلا أنهم يعملون في الخفاء وبسرية تامة، لنجدهم في نهاية أحداث الرواية يعلنون فوزهم بالسباق، كما يعلنون ميلاد دولة عظمى جديدة، وهي أمريكا. 
Mohammed Eid A Alotaibi

وبعد سيطرة هذا الخصم على السيادة، وانفصال الذات"بيتر " عن تحقيق موضوع القيمة، نجد أن بعض المساعدين يتحولون إلى خصوم لتلك الذات، فشيرين بعد العلاقة الحميمة مع

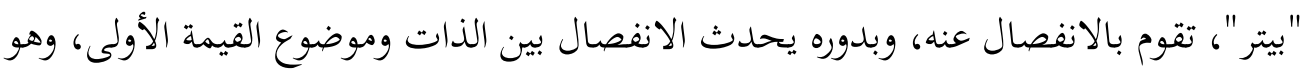

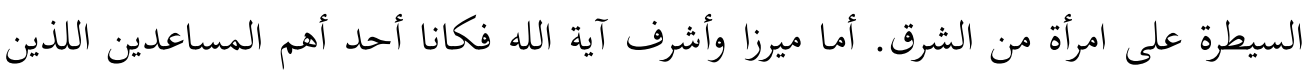
تعتمد عليهما الذات "بيتر"، نجدهما بعد سقوط حكم العجوز، وإقامة دولة جديدة تحت النفوذ الأمريكي، يذهبان لينضما إلى تلك القوة الجديدة، ويصبحا بعد ذلك أحد مساعديها، بتوليهما مناصب عليا في تلك الدولة الجديدة. ويمكن أن نستنتج مما سبق أن الذات"بيتر" سعت إلى تحقيق موضوع القيمة، من خلاهل

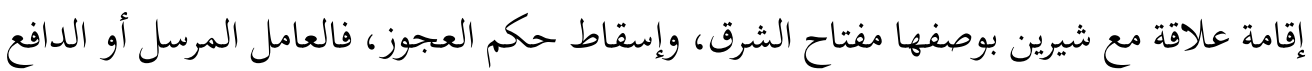
هو السيطرة على موارد النفط في الشرق. أما المساعدين للذات"بيتر" فهم: شيرين وعبّاس وميزرا وأشرف أية الله، وبريطانيا العظمى. وأما الخصوم فهم على نوعين: النوع الأول: الخصوم الثابتون، وهم: العجوز حاكم الدولة، والخصم الخفي الأمريكان، والنوع الثاني: الخصوم المتحولون، وهم: شيرين، وميززا، وأشرف آية الله.

الخلاصة

وفي ختام البحث يمكن أن نستعرض أهم النتائج التي تم التوصّل إلى أن البعد الجسمي يعد جزءا مهما في بناء الشخصية الرئيسة، لأنه يسهم بصورة قوية في إقناع القارئ بواقعية الشخصية، حيث اعتمد الراوي في الكشف عنه من خلال طريقتين: الطريقة الأولى طريقة الإخبار، والطريقة الثانية طريقة الإظهار. أن البعد النفسي يكشف للقارئ عن الصراعات النفسية التي تعيشها شخصيات الرواية ومكامنها الداخلية. عمد الكاتب إلى اختيار تقنية الرؤية الثنائية التي تجمع بين الراويين -الراوي الخارجي والراوي الداخلي- للحد من سلطة الراوي المطلقة على حرية الشخصيات الروائية. اهتم الروائي بعلاقة الاسم ودلالته بالشخصية في معظم شخصياته، حيث تظهر في سياقات الحكي بدلالاتها الموحية التي تقوم بعقد صلات بين

$$
\text { مدلول اسم الشخصية، ومجريات أحداث الرواية. }
$$



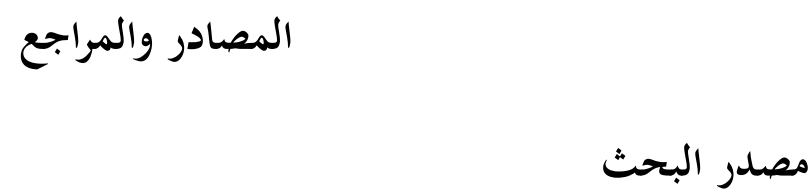

Munīf, A. A. (1999). Sibāq Al-Masāfāt Al-Ṭawilä̈ (4 ed.). Beirut: alMu'assä̈ al-' Arabīyaẗ liddirāsāt wa al-Našr.

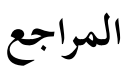

Abbas, F. (1982). Al-šahșìyä̈ fi dạ̄' al-Taḥlìl al-Nafsì. Beirut: Dar AlMassira.

Abbas, F. (1990). Asālīb Dirāsä̈ al-šahsșiyaẗ. Beirut: Dar Al Fikr Al Lubnani.

Abdelfatah, O. (1982). Binā' al-riwwāyah. Cairo: Maktaba Al-šabāb.

Al-Ba'albakī, M. (1998). Al-Maurid (32 ed.). Beirut: Dār al-'Ilm lilmalāyin.

Al-Ğabūrī, A. R. (2012). Binā' Al-Riwāyä̈ 'Inda Hasan Mațlak. AlIskandarīyä̈: Al-Maktab Al-Ǧāmi'î Al-Ḥadịt.

Al-hūrī, F. A. (1876). Kanz Luğāt. Beirut: Maṭba'ä̈ Al-ma'ārif.

Al-Kurdī, A. A. (1996). Al-Rāwwiy Wa al-Naș Al-Qașașī (2 ed.). Cairo: Dār al-Našr lilğāmi' āt.

Anīs, I., Muntașr, A. al-ḥalīm, Al-ṣawāliḥ̄ī, A., \& Aḥmad, M. hֵalfullah. (2004). Al-Mu'ğam al-Wasiț (4 ed.). Cairo: Maktabä̈ al-šurūq alDaūlīyä̈.

El-Eid, Y. (2010). Taqnīāt Al-Sard Al-Riwā̄ 'ì (3 ed.). Beirut: Dār al-Fārābī. Hilal, M. G. (1997). Al-Naqd Al-Adabi Al-Hadīt. Cairo: Nahdet Misr Publishing Group.

Ibn Manẓūr. (1993). Lisān al- 'Arab (3 ed.). Beirut: Dār Ṣādr Linšr. 
Mohammed Eid A Alotaibi

Ibrahim, F. (1986). Mu'ğam Al-Mușțalaḥāt al-Adabìyä̈. Sfax: AlMu'ssasaẗ al-'ArAbīyä̈ lin-Nāšrīn Al-Mutahiidä̈.

Laḥmidānī, Ḥamīd. (1991). Bunìyä̈ al-Naṣ al-Saradī. Beirut: al-Markaz alTakafi al-arabi.

Murtad, A.-M. (1998). F̄̄ Naz̧rìyä̈ Al-Riwāyä̈. Kuwait: 'Ālam Al-Ma' rifẗ Al-Mağlis Al-Wațanī Llțqāfä̈ Wāl Funūn Wāl 'Ādāb.

Zeitouni, L. (2002). Mu'ğam Muștalahạt Naqd Al-Riwayä̈. Beirut: Dār alNahār. 